Outsourcing IT for Small Hotels: The Opportunities and Challenges of Using Application Service Providers

\author{
Alexandros Paraskevas \\ Oxford Brookes University \\ School of Hotel and Restaurant Management \\ Oxford OX3 0BP, UK \\ Tel: $+44(0) 1865483835$ \\ Fax: +44(0)1865 483878 \\ E-mail: aparaskevas@brookes.ac.uk \\ and \\ Dr Dimitrios Buhalis \\ University of Surrey \\ School of Management Studies for the Service Sector \\ Guilford GU2 7XH, UK \\ Tel: $+44(0) 1483686332$ \\ Fax: +44(0)1483686301 \\ E-mail: d.buhalis@surrey.ac.uk
}




\section{Outsourcing IT for Small Hotels: The Opportunities and Challenges of Using Application Service Providers}

From the early ages of the Internet's commercial use, several authors outlined the unprecedented opportunities for small businesses ${ }^{1}$. It was suggested that the Internet would benefit organizations in the areas of communications, personnel, sales, advertising and business intelligence. The Internet would also potentially support innovative small businesses and even individual entrepreneurs to develop their virtual size and to compete with much larger corporations, almost on equal footing. This was mainly due to the unprecedented resources available to virtually any innovative and knowledgeable entrepreneur with a PC and a modem. Another prediction suggested that the Internet would enable small businesses to reach a larger market and appeal to many different segments. As a result, all businesses would effectively be internationalized regardless whether they wished and planned for that or not ${ }^{2}$.

However, the proliferation of the Internet achieved a lot more for many organizations as it forced a revolution in business practices globally. Influential authors such as Ohmae ${ }^{3}$, Brynjolfsson and Kahin ${ }^{4}$ claim that the 'New' or 'Digital' Economy, ended Porter's classic value chain. A new 'digital value system' ${ }^{5}$ has emerged and new business models, the 'MetaMarkets' ${ }^{\prime}$, were formed in which companies move away from asset-intensive structures and towards internet-leveraging styles of operation forming networks that continuously replace elements of their operation with more efficient outside partners.

PricewaterhouseCoopers ${ }^{7}$ suggest that these web-enabled networks go beyond driving cost savings and supply chain efficiency. By combining and leveraging core competencies, tangible and intangible assets of their connected parties, they can add value that exceeds customer expectations and are able to create a new type of advantage: the collaborative advantage . They propose two "key types of creative partnerships" for the New Economy's business environment:

- Front-end or customer facing alliances that create new ways to increase business, and

- Back-end partnerships, aiming at improving the technical infrastructure, streamlining the supply chain management and procurement, as well as leveraging the information assets of the connected parties.

Hospitality industry has realized the need of such partnerships long before the Internet revolution. In the mid-80s large chains moved to partnerships with airlines and car rental companies to support their customer loyalty programs. They also built alliances with other

\footnotetext{
${ }^{1}$ For example, Guthrie, R.A. and Austin, L.D. (1996), "Competitive Implications of the Internet", Information Systems Management, Vol. 13, No. 3, Summer, pp. 90-93. Also see Eckhouse, J. (1998), "Technology Gives Edge to Smaller Businesses", InformationWeek, No. 711(Nov 30), SR2-SR4.

${ }^{2}$ Oviatt, P. and McDougal, B. (1998), "Accelerated Internationalization: Why Are New and Small Ventures Internationalizing in Greater Numbers and with Increasing Speed?" paper presented in the conference Globalization and Emerging Businesses: Strategies for the 21st Century, The Dobson Centre for Entrepreneurial Studies, McGill University, Montreal, Canada (September).

${ }^{3}$ Ohmae, K. (2001), The Invisible Continent: Four Strategic Imperatives of the New Economy, Nicholas Brealey Publishing Ltd.

${ }^{4}$ Brynjolfsson, E. and Kahin B. (Eds.) (2000), Understanding the Digital Economy, The MIT Press.

${ }^{5}$ Cronin, M. J. (2000), Unchained Value: The New Logic of Digital Business, Harvard Business School Press.

${ }^{6}$ Means, G. and Schneider D. (2000), Meta-Capitalism: The E-Business Revolution and the Design of $21^{\text {st }}$-Century Companies and Markets, PricewaterhouseCoopers.

${ }^{7}$ Skrovan, S.J. \& Pollack, E. (2000), "Creative Partnerships: Key Asset of the New Competition", Critical Issues, August, PricewaterhouseCoopers.
} 
chains to gain entrance and acceptance in foreign markets, and allied with restaurant chains to improve their food and beverage provision. The Internet came as a medium to further facilitate such strategic moves. It opened further horizons of collaboration with companies that could help them create a more compelling offer to their clientele and even work with traditional competitors in order to increase efficiencies in their back-of-the-house. For example, Avendra.com, the largest procurement service company which was formed in early 2001 by Marriott International, Inc., Hyatt Hotels Corporation, ClubCorp. USA, Inc., Six Continents Hotels, and Fairmont Hotels \& Resorts, to support their procurement function through collaboration.

Many small independent hoteliers have implemented the first type of partnership (front-end) They joined consortia (e.g., Best Western) that enabled marketing activities, international representation and access to global distribution systems which would not be otherwise possible to them. Others have linked their business with private or public tourism product distribution channels such as hotel representation organizations (e.g., WorldRes, Utell or Lexington Services), computer reservation systems (e.g., Galileo) or destination management systems (e.g., Gulliver in Ireland). In many cases the Internet has helped them to team-up with other small hotels or Destination Management Organizations in their area to offer better service solutions, to collaborate on website content, as well as in cross-promotions and multichannel alliances.

Looking at back-end partnerships, there is evidence of web-enabled networking to streamline supply management with several vertical hospitality e-marketplaces both in US (purchasepro.com, goco-op.com) and in Europe (yassas.com in Greece, hospitalia.com in Italy, HotelnetB2B.com in Spain, etc.). Similarly, an increasing number of independent hoteliers seem to use the web-enabled "knowledge repositories" created by tourist boards (such as the ITN - Illinois Tourism Network ${ }^{8}$ ) or large consulting companies (such as ArthurAndersen's hotelbenchmark.com). However, little evidence exists on the use of webenabled partnerships to improve the information and communication infrastructure in small hotels. Research has shown that independent hoteliers are reluctant to invest on information and communications technology (ICT) for reasons ranging from lack of capital to lack of IT literacy and techno phobia ${ }^{9}$.

One of the most recent developments in the Internet arena is the ability of organizations to deliver and manage applications and computer services through remote data centers. At the stage of their conception, these organizations, called Application Service Providers (ASP), were regarded as the best means for small and medium sized businesses to create an affordable ICT infrastructure without requiring massive investment ${ }^{10}$. However, with only few exceptions ${ }^{11}$, this model does not seem to be widely embraced by small independent hoteliers.

\footnotetext{
${ }^{8}$ See http://www.ILtourism.net

${ }^{9}$ Main, H. (1995), "Information Technology and the Independent Hotel - Failing to Make the Connection?", International Journal of Contemporary Hospitality Management, Vol. 7, No. 6, pp. 3032. Also, Siguaw, J.A., Enz, C.A. and Namasivayam, K. (2000), "Adoption of Information Technology in U.S. Hotels: Strategically Driven Objectives", Journal of Travel Research, Vol. 39, No. 2, pp.192-201.

${ }^{10}$ Weller, T.C. (1999), "Application Hosting Market", Equity Research: Industry Update, Legg Mason Wood Walker Inc. (December, 30). Also, Yankee Group (1999), "SMBs + ASPs = Opportunities?", The Yankee Report, Dec 12.

${ }^{11}$ Heart, T. and Pilskin, (2002), "Can Application Service Providers Enable Cost-Effective Information Technology for Travel and Tourism?", in K.W. Wöber, A.J. Frew and M. Hits (eds.), Information and Communication Technologies in Tourism 2002, proceedings of the IFITT conference, Innsbruck, Austria.
} 
This article explores the views of European small independent hoteliers towards a type of back-end 'internetworking' with ASPs aiming at the improvement of their ICT infrastructure. By reviewing the theory and reality of the ASP model deployment, its benefits and its adoption practicalities in the hospitality industry, the article aims at demystifying the concept and show that independent hoteliers should overcome their barriers and start regarding ASPs as ICT partners in the New Economy. However, the decision-making process related with ICT in independent small properties should be re-considered and clear criteria determining this 'partnership' need to be established.

\section{Application Service Providers in the Hospitality industry}

An Application Service Provider (ASP) is "a third party service firm which deploys, manages and hosts remotely a software application through centrally-located servers in a 'rental' or lease agreement"12. ASPs host a number of business applications, which are distributed to a wide range of customers across the Internet. ASP customers include individual firms that 'rent' the same software for a fee. For example, some hotel firms may 'rent' their Property Management System's (PMS) software application from supplier Micros/Fidelio. ASPs primarily aim at smaller businesses, which have less financial resources and technological expertise, rather than larger companies with extensive ICT departments and in-house provision and support. The ASP provider is responsible for either directly or indirectly providing specific activities and technical 'know-how'.

According to the International Data Corporation ${ }^{13}$ the defining characteristics of an ASP are the following:

- It is application centric. The ASP provider offers access to and management of an application, which is available in the market.

- It 'sells' application access. Hotels have access to a software application without having to make up-front investment in licenses, servers, people and other resources. Hotels do not 'own' the application. They just pay a fee to 'use/rent' it. The software may either be owned by an ASP or be distributed by one, under contractual agreement with its vendor.

- It is centrally managed. Services and data are managed through a central remote location. The hotel may manage locally only the results of the application.

- It offers a one-to-many service. The ASP generally develops partnerships with vendors to provide the deployment and management of packaged or standardized software applications that can be accessed by more than one hotels. Minimal or no customization is provided for each property.

- It delivers on the contract. The ASP is the sole responsible for the delivery of the services described in the contract (Service Level Agreement - SLA) with the hotel. It may or may not control all the components of the provision (network, platform, applications, operations, end-services) but it is responsible for performance across all of them ${ }^{14}$.

There are several pricing models for ASP services. Usually each hotel pays a flat fee to sign up and a monthly fee for gaining access to the application, training, expert support and free upgrades (new drivers and features). However, other payment schemes are also available, based on usage rates, such as fees per transaction, number of screen clicks or amount of usage time.

\footnotetext{
${ }^{12}$ Cherry Tree and Co. (2000), $2^{\text {nd }}$ Generation ASPs: Spotlight Report, September.

${ }^{13}$ International Data Corporation (1999), The ASPs' Impact on the IT Industry: An IDC-Wide Opinion, Document No. 20323 (September).

${ }^{14}$ Apfel, A. (2000), Application Infrastructure and Operations - SAP, Research Note M-12-1321, Gartner Group Inc., 6 November.
} 
ASPs are divided in 'horizontal' and 'vertical' service providers. Horizontal ASPs offer the same application regardless of the industry to which it is provided - normally generic CRM and back-office applications, such as general accounting or human resource management applications. Vertical Service Providers (VSPs) zero in on discrete niches, establishing definite boundaries regarding what they are, what they do and the sectors which they are targeting by offering industry-specific applications ${ }^{15}$. Hospitality application hosts are both horizontal and vertical, although "one-stop-shopping" VSPs appeal more to the sector ${ }^{16}$.

The emergence of the web-enabled application hosting resulted to a proliferation of ASP companies, similar to the explosion of the 'dot-coms'. This dramatic growth in the ASP sector blurred the distinction between software and service provision, although quite often both are offered by the same organization. Heinlein ${ }^{17}$ identifies four distinct business models for ASPs, namely: resellers, aggregators, pure-plays, and business process outsourcers (hospitalityspecific examples in Exhibit 1). These business models have received a fairly good response, mainly by large hotel companies.

- Resellers normally package an application/product from another software provider and resell it to end-customers on a discounted basis. They typically charge hotels for the use of the application and provide the first level of support. They do not have much control over the application, but are experts in the specific market they operate and usually 'own' the customer. Normally resellers combine their own products with the re-sold applications, in a bundle package offering and supporting several additional functions. Resellers are not normally responsible for maintaining the application from either a technical or product perspective, beyond first level of support .

- Aggregators combine and distribute multiple applications from different ASPs. These applications are usually offered through a portal with a single sign-on. The use of multiple applications allows aggregators to offer hotel-specific packages (such as Property Management Systems, Point Of Sales systems, Yield Management, etc.) or business-wide packages (such as Human Resources Management, training, accounting, back-office, etc.). By offering more applications and a comprehensive service, they enable hotels to deal with a limited number of ASPs. This model is ideal for hotels wanting a 'one-stop' application service provision. However, aggregators do not usually offer 'best-of-breed' applications and some of their products are usually weaker than others available in the market.

- Pure-plays normally have their own data centers where they maintain, develop and offer the applications themselves, typically 'best-of-breed' ones. They therefore rely least on partnerships to deliver their applications. They have a high level of control over the service and customer experience and offer end-to-end accountability. Although this is often the most costly of all models, many organizations want their ASP to offer them the 'safety' of a pure-play, particularly if they are running critical business applications. Pure plays frequently use resellers who target or have access to markets that pure-plays are not directly interested in.

- Business process outsourcers can be either resellers, aggregators, or pure-plays. The distinction is that they deliver business process outsourcing services in addition to

\footnotetext{
${ }^{15}$ McCabe, L. (2001), "VSPs Bloom in the ASP Microclimate", ASPnews.com, E-mail Update No. 78, [On-line], Available:

http://www.aspnews.com/analysis/analyst_cols/article/0,2350,4431_587851,00.html [2000, Feb 19].

${ }^{16}$ Chrestman, C. (2000), "ASP is Here to Stay", Hospitality Upgrade, Jun 16, Counterpoint, p. 10

${ }^{17}$ Heinlein, S. (2001), "Crash Course for ASPs", [On-line], Available:

http://www.aspnews.com/analysis/analyst cols/article/0,,4431 592331,00.html [2001, February 16].
} 
application services to the customer. They usually manage, support and integrate both hospitality-focused and business-wide applications. This model of ASP can be compared to a professional service organization. The disadvantage of this model is that it relies on several partnerships, similar aggregators and demands both creativity and simplicity in its packaging.

Exhibit 1. Hospitality ASP Taxonomy

\begin{tabular}{|c|c|c|c|c|}
\hline & Resellers & Aggregators & Pure-Plays & $\begin{array}{l}\text { Business Process } \\
\text { Outsourcers }\end{array}$ \\
\hline Example & $\begin{array}{l}\text { Interval } \\
\text { International/ } \\
\text { CCSI }\end{array}$ & $\begin{array}{l}\text { HotelTools/ Radiant } \\
\text { Systems }\end{array}$ & $\begin{array}{l}\text { Pegasus Solutions } \\
\text { Inc. }\end{array}$ & Accuvia \\
\hline $\begin{array}{l}\text { Target } \\
\text { Market }\end{array}$ & $\begin{array}{l}\text { Market directly } \\
\text { associated with } \\
\text { the company (e.g., } \\
\text { vacation } \\
\text { ownership } \\
\text { industry) }\end{array}$ & $\begin{array}{l}\text { Small or larger hotel } \\
\text { organizations }\end{array}$ & $\begin{array}{l}\text { Mainly hotel chains } \\
\text { but also any } \\
\text { individual } \\
\text { properties } \\
\text { interested in a } \\
\text { Property } \\
\text { Management } \\
\text { solution }\end{array}$ & $\begin{array}{l}\text { Fortune } 500 \\
\text { organizations in } \\
\text { the hospitality, } \\
\text { foodservice and } \\
\text { retail industries }\end{array}$ \\
\hline $\begin{array}{l}\text { Business } \\
\text { Activity }\end{array}$ & $\begin{array}{l}\text { Provides own } \\
\text { software along } \\
\text { side with partners' } \\
\text { suites and support } \\
\text { (e.g., the } \\
\text { comprehensive } \\
\text { timeshare } \\
\text { application Resort } \\
\text { Solutions @ } \\
\text { alongside with } \\
\text { SoftBrands' } \\
\text { Hospitality suite } \\
\text { as an ASP } \\
\text { solution). }\end{array}$ & $\begin{array}{l}\text { Provides proprietary } \\
\text { software on main } \\
\text { hotel IT functions } \\
\text { alongside } \\
\text { multiple applications } \\
\text { from different ASPs } \\
\text { (e.g., call accounting, } \\
\text { general accounting; } \\
\text { back office; data } \\
\text { cleansing; } \\
\text { procurement; } \\
\text { electronic } \\
\text { presentation } \\
\text { ePayment; etc.). }\end{array}$ & $\begin{array}{l}\text { Provides its } \\
\text { proprietary } \\
\text { Property } \\
\text { Management } \\
\text { module (Pegasus } \\
\text { Central) as a single- } \\
\text { image inventory } \\
\text { system, offering } \\
\text { traditional property } \\
\text { management } \\
\text { system functions } \\
\text { and connectivity } \\
\text { with distribution } \\
\text { channels. }\end{array}$ & $\begin{array}{l}\text { Provides business } \\
\text { process } \\
\text { outsourcing } \\
\text { services } \\
\text { addition } \\
\text { application } \\
\text { services. } \\
\text { example } \\
\text { manages, supports } \\
\text { and integrates } \\
\text { both hospitality- } \\
\text { focused } \\
\text { applications such } \\
\text { as POS, PMS, } \\
\text { yield management } \\
\text { systems as well as } \\
\text { business-wide } \\
\text { applications such } \\
\text { as finance, HR } \\
\text { and CRM. }\end{array}$ \\
\hline
\end{tabular}

\section{The ASP Value Proposition}

The concept of 'hosted application' is not new. In the 1960s mainframes (known also as 'bureaus') offered a centralized computing model, which allowed several users to share the same computer process capacity. Mainframes were mainly used by large organizations and governmental bodies to co-ordinate all their operations on a global basis. This model, however, required high up-front costs, long deployment and implementation time, was costly to use and difficult to upgrade. Text-based interfaces and the inherent inflexibility of mainframes were considered counter-productive and soon technological evolution enabled smaller and more flexible machines to perform the same job. 
The ASP model provides similar services to what the mainframe model did for single organizations. The main difference is that ASPs may support a wider number of organizations simultaneously with a much more dynamic and interactive platform, which is affordable even by small businesses. Effectively these businesses may outsource their service needs and pool resources to achieve economies of scope.

Industry experts suggest that ASPs are ideal for hotels, especially for smaller- to mid-sized ones, that "want to leverage the best vertical and business support applications on the market without having to deal with the technology or pay for more functionality than needed"18. As they do not have extensive ICT departments and expertise, they can easily access up-to-date applications and benefit from the collective knowledge accumulated by ASP providers without having to invest extensively in technology or expertise building. Although lowering costs and complexity is a major advantage, the model also gives organizations more time to concentrate on their core competencies, allowing them to decide when and where to access their data ${ }^{19}$.

In general, ASP benefits can be classified into two main categories: bottom-line and top-line benefits (Exhibit 2). Bottom-line benefits enable organizations to manage their resources better and to reduce their costs. By sharing research and development costs with others, small hotels can maintain up-to-date systems at an affordable cost. Top-line benefits create further value, improve customer service, and enable organizations to improve their service provision and to add value to their provision. These benefits can improve the competitiveness and profitability of an organization.

\footnotetext{
${ }^{18}$ Rambler, M. and McGrew, G. (2000), " The Case for ASPs: Opportunities and Challenges With the ASP Model", Lodging Magazine, December, [On-line], Available: http://www.cyntercorp.com/sections/news_articles/articles/200012ASP.asp [2001, March 13]

${ }^{19}$ Jacobs, S. (2000), "ASP-iring Technology", The CPA Journal, Vol. 70, No.11, November, p. 66. Also, Fantasia, A. (2000), "Decoding ASPs", Harvard Business Review, Vol. 78, No. 6, Nov/Dec, p. 33.
} 
Exhibit 2 - The ASP Value Proposition

\begin{tabular}{|c|c|}
\hline $\begin{array}{l}\text { Bottom Line Benefits } \\
\text { (Cost saving) }\end{array}$ & $\begin{array}{l}\text { Top Line Benefits } \\
\text { (Creating/Adding Value) }\end{array}$ \\
\hline $\begin{array}{l}\text { - Costs spread more evenly through time as } \\
\text { opposed to massive up-front infrastructure } \\
\text { investments. } \\
\text { - ICT cash flows are predictable and can be } \\
\text { managed over the application's life cycle. } \\
\text { - No need to buy, maintain and upgrade in- } \\
\text { house hardware and software. Only } \\
\text { requirement is a PC with a Web browser, a } \\
\text { modem and a high-speed connection. } \\
\text { - Regular upgrades of the hosted applications } \\
\text { are automatic, without significant cost } \\
\text { implications and with little or no interruption } \\
\text { to service. } \\
\text { Cost savings from sharing cost of specialized } \\
\text { ICT personnel, training and expensive } \\
\text { consultancy services }\end{array}$ & $\begin{array}{l}\text { - } 24 \text { hours X } 7 \text { X } 365 \text { days high quality } \\
\text { technical support. } \\
\text { - Ability to focus on core competencies of the } \\
\text { business. } \\
\text { - Access to 'best-of-breed' application suites a } \\
\text { an affordable cost. } \\
\text { - Increased scalability (for more operating units } \\
\text { or franchisees). } \\
\text { - Flexibility to switch to another provider. } \\
\text { - Minimized ICT risk. } \\
\text { - Minimized administrative burden through the } \\
\text { use of ASP's specialized support and } \\
\text { expertise. } \\
\text { - Reduced application deployment time. } \\
\text { Training on application use provided as part of } \\
\text { the package. }\end{array}$ \\
\hline
\end{tabular}

\section{A Reality Check}

No matter how attractive this model looks, the early adopters were faced with quite a few problems, which the ASP industry is addressing as it moves from its developing stage to maturity. The main problem has been the stability of the providers themselves ${ }^{20}$. Similarly to many 'dot.coms', the ASP dramatic growth in 1999 and early 2000 led to a collapse of many prominent providers. That resulted in a lot of unsatisfied ASP customers, who had to deal with the operational problems that this collapse caused. Many early adopters lost faith on ASPs and went back to more conventional ICT provision. This shake-up is expected to continue until 2003, before half of the existing ASPs or small service providers fail or merge with larger players who will eventually offer the stability needed in this marketplace ${ }^{21}$.

In addition, the performance of certain ASPs has not matched the service level agreements and the expectations of their consumers. Some applications were not as scalable as needed, resulting to delays and frustration. As the ASP customer base was increasing users often had to wait on line for service. In addition, several connectivity and access problems were reported, due to heavy Internet traffic or during periods of unreliable system availability. This was particularly critical for hotel PMS applications, as they affected directly its core business and jeopardized the guest service experience. For example, speed of check-in and check-out,

\footnotetext{
${ }^{20}$ Koch, C. (2001), "Boy, That Was Fast!", CIO Magazine, Nov. 15, [On-line], Available: http://www.cio.com/archive/111500/boy.html, [2001, Feb. 08].

${ }^{21}$ Friedlander, D. (2001), "Bain Capital's Investment in USi Is Indicative of Consolidation in the ASP Market", Giga Information Group Analysis, [On-line],

http://www.gigaweb.com/search/1,2197,results,00.html?iContentID=258753 [2001, October 28].
} 
availability of guest billing information, etc. was often problematic when access to ASP was slow. Until broadband connectivity is available in every location, connection speed and data transport capabilities, necessary to support the 'hosted application' model varies according to the local Internet Service Providers capabilities. This generates a sense of unpredictability and unreliability, which jeopardizes the benefits offered by ASPs and raises concerns about the services they can actually provide as well as the degree of control they have over the service they promise.

Security has also been a concern. The fact that company-critical data must travel a long way in order to get back (through a telecommunications company network to an Internet Service Provider and then finally to the ASP) and forth (the same route to reach the user's screen) represents a high risk for security breaches by hackers who would may try to access accounting, employee or customer data. Many businesses are therefore nervous to allow their critical data to travel in the cyber space.

Finally, many potential ASP adopters were put off by the idea that they would not 'own' the data produced by the hosted application any more. This created a sense of insecurity and concern especially by small business owners/managers who often feel they should control all aspects of their operations. An early study of the perceptions of small-hotel managers showed that this loss of direct control on the application would cause a lot of apprehension from the traditional power centers in a hotel (owner, manager, controller, etc.) ${ }^{22}$. Hence, adoption of the ASP model would imply a major and - in some cases - painful change in the hotel's organizational culture.

\section{The Study}

One methodological challenge in this effort to document the small-hotel managers' perception of the application hosting model was the selection of hotels for inclusion in the study. The existing European Commission or Small Business Administration definitions, which classify firms according to the number of employees are not universally accepted. The present study included hotels that fit the following definition offering a quantitative dimension to the sampling process:

"A small hotel is financed by one individual or small group, directly managed by its owner[s] in a personalized manner and not through the medium of a formalized management structure. It may or may not be affiliated to an external agency on a continual basis for at least one management function. In comparison to the largest unit of operation within the hotel industry it is perceived as small, in terms of physical facilities, production/service capacity, and number of employees."23

Another criterion used for the sample selection was whether the hotel had a web-presence, which indicated a minimum level of Internet awareness. Only hotels with an Internet presence were targeted in order to ensure that they had a minimum degree of ICT understanding and usage. A convenience sample of $420 \mathrm{UK}$ and Greek independent hotels of size that varied between 50 and 150 rooms was selected. An open-ended question survey was sent by e-mail to all hotel managers/owners in the sample. E-mail surveys present a number of advantages compared to the regular mail surveys. Researchers have found that apart from the cost

\footnotetext{
${ }^{22}$ Paraskevas, A. (2001), "ASP: The Affordable IT Answer for Small and Medium-Sized Hospitality Businesses?", paper presented in the conference Entrepreneurship in Tourism and the Contexts of Experience Economy, University of Lapland, Rovaniemi, Finland (April).

${ }^{23}$ Morrison, A.M. (1998), "Small Firm Statistics: A Hotel Sector Focus", The Service Industries

Journal, Vol. 18, No.1, pp. 132-142.
} 
benefits that this method offers data can be collected in a significantly smaller timeframe ${ }^{24}$. Although there is no documented evidence that e-mail surveys produce higher rate of response than postal surveys ${ }^{25}$, this survey produced a response of $25.2 \%$ (106 usable responses) which is considered satisfactory. Exhibit 3 illustrates the respondents' profiles.

Exhibit 3. Respondents' Profiles

\begin{tabular}{|l|l|l|}
\hline & N = 106 & \% \\
\hline Position in the Hotel & & \\
Owner/Manager & 47 & 44.3 \\
General Manager & 28 & 26.4 \\
Assistant GM & 12 & 11.4 \\
Financial Controller & 8 & 7.5 \\
$\quad$ Sales \& Marketing Manager & 11 & 10.4 \\
Age $\quad$ & \\
$\quad$ Less than 25 y.o. & 18 & 17.0 \\
25-35 & 26 & 24.5 \\
36-45 & 34 & 32.1 \\
46-55 & 23 & 21.7 \\
More than 55 y.o. & 5 & 4.7 \\
ICT competence & & \\
High & 7 & 6.6 \\
Average & 21 & 19.8 \\
Low & 78 & 73.6 \\
Hotel Type & & \\
City hotel & 47 & 44.3 \\
Resort Hotel & 41 & 38.7 \\
Other & 18 & 17.0 \\
Hotel Capacity & & \\
50-99 rooms & 43 & 40.6 \\
100-150 rooms & 63 & 59.4 \\
\hline
\end{tabular}

The data collected was analyzed by content analysis in two stages ${ }^{26}$. The initial stage involved developing a coding scheme and coding text from all 106 e-mailed responses and identifying general themes in the data. Responses were then assigned to each theme to better understand the relative frequency of occurrence of each. Intercoder reliability was evaluated by 'Cohen's $\mathrm{Kappa}^{\prime 27}$, giving a .92 coefficient for the themes identified and the responses per theme, which shows high intercoder reliability.

The survey was designed to reflect the respondents' general attitude towards using the Internet to outsource ICT applications, regardless of their ASPs' awareness. The respondents showed

\footnotetext{
${ }^{24}$ Parker, L. (1992), "Collecting Data the E-mail Way", Training and Development, July: pp. 52-54. Also, McCullough, D. (1998), "Web-Based Market Research: The Dawning of a New Era", Direct Marketing, Vol. 61, No.8, pp. 36-39.

${ }^{25}$ Mehta, R., \& Sivada, E. (1995), "Comparing Response Rates and Response Content In Mail Versus Electronic Mail Surveys", Journal of the Market Research Society, Vol.17, No.4, pp. 429-440.

${ }^{26}$ Krippendorff, K. (1980), Content Analysis: An Introduction to Its Methodology, Thousand Oaks, CA: Sage Publications.

${ }^{27}$ Hughes, M.A. and Garrett D.E. (1990), "Intercoder Reliability Estimation Approaches in Marketing: A Generalizability Theory Framework for Quantititative Data," Journal of Marketing Research, Vol. 27, No. 2, pp. 185-195.
} 
a good level of ASP awareness (53.8\%), higher than in a previous study ${ }^{28}$. For the unaware respondents, a half page briefing on ASPs, their value proposition and the web-address of ASPIC (the ASP Industry Consortium ${ }^{29}$ ) were attached to the e-mail survey for further information.

\section{Small-Hotel Managers Perception of and Involvement in ICT}

Surprisingly, almost all of the respondents (92.5\%) either stated or implied that they do not perceive ICT as a means to gain competitive advantage. The general view was that ICT has an ancillary, supporting role in the hotel business. With ICT "things have just become easier". However, some respondents felt that they "can still manage [their] hotel without [ICT]". The majority of the respondents viewed ICT as tools for enhancing their efficiency by:

- improving information processing (e.g., through guest history, arrivals and departures lists, etc.),

- developing planning and control (through effective use of reports generated),

- enhancing some work processes (by eliminating mundane tasks),

- saving time and effort in a number of administrative functions (e.g., guest accounting, reservations, marketing), and

- reducing costs (predominantly labor costs and specific jobs such as for example, night auditing).

Small-hotel managers did not regard ICT as a source of competitive advantage. They felt that it is their core functions that give them the edge and this is where they should concentrate. The majority of the respondents classified the various ICT applications in their hotels as 'commodities' rather than as 'differentiators' and therefore their ICT applications do not distinguish their property from its competitors. However, they often considered one or two applications (mainly PMS and accounting) as 'critical' for their hotel and emphasized that properties with weaker applications in these areas may face competitive disadvantage. This is in line with some of the new way of strategic ICT thinking ${ }^{30}$, suggesting that ICT cannot offer sustainable competitive advantage, although innovative organizations need to adopt ICTs and take advantage of the changes observed in the marketplace.

Exhibit 4, shows the respondents' degree of involvement with ICT decisions in their hotel. Almost half of the respondents $(48.1 \%)$ stated that they are not directly involved with ICT decisions and probably use the services of either internal or external ICT experts/consultants. Further, more than the $2 / 3(69.8 \%)$ of the respondents admitted that they are often intimidated by the complexity of ICT and are unable to follow its continuous changes and improvements. In the same theme, $17 \%$ of the respondents reported some good knowledge of ICT, while only $24.5 \%$ of the rest stated that they were either considering to become more knowledgeable in the near future or to encourage their staff to become more ICT literate.

\footnotetext{
${ }^{28}$ Paraskevas, A. (2001), op. cit.

${ }^{29} \mathrm{http}: / / \mathrm{www}$.aspindustry.org

${ }^{30}$ Porter, M. (2001), "Strategy and the Internet", Harvard Business Review, March, Vol.103, pp.63-78.
} 
Exhibit 4 - Knowledge and Involvement of Owner/Manager

\begin{tabular}{|l|l|l|}
\hline Degree of Involvement & N & \% \\
\hline Remote from ICT management / use & 6 & 5.7 \\
\hline Limited involvement in an overseeing capacity & 14 & 13.2 \\
\hline Close involvement in use and ICT decisions & 31 & 29.2 \\
\hline Direct involvement in use and decision making & 48 & 45.3 \\
\hline $\begin{array}{l}\text { Regular daily direct interaction with hotel's ICT (use and technical } \\
\text { aspects) }\end{array}$ & 7 & 6.6 \\
\hline
\end{tabular}

\section{Views on ASPS}

In exploring their views on ASPs, one factor that some respondents felt that make this model appealing is "the ICT expertise in business applications" it offers. Most of the hoteliers (79.2\%) found the idea of "24/7 technical support" attractive, while more than half linked that with cost savings in expert ICT staff or consultants. The responses clearly indicated that using an ASP would just give hoteliers the opportunity to improve their present use of ICT and relieve them from "maintenance headaches". In their views, ASPs are providing the small hotel with 'relative' advantage, i.e., better innovation than its precursor.

However, only $39.6 \%$ of the respondents reported that they were interested to further investigate the possibility of using an ASP, while the rest dismissed the idea for various reasons that are presented later in this section.

In a further exploration of their interest, the pro-ASP respondents indicated a number of reasons for their interest, which can be classified in 3 major categories:

- reduction of business costs (mainly labor),

- reduction of ICT costs (mainly through eliminating ICT upgrading costs, maintenance, and ICT experts) and

- improvement of ICT performance (access to best-of-breed applications, upgrading existing ones, etc.).

Still, more than half of the pro-ASP respondents (64.3\%) would consult an expert before making this decision, while the rest stated that they will make an informed decision by themselves. Of those interested in ASP solutions, the vast majority would investigate the possibility of selective partnering with ASPs, whilst keeping their 'critical' applications, such as PMS in the hotel. Only a 7\% were interested in a total partnering solution indicating their interest in a business process outsourcer. When asked to indicate which applications they would prefer to use through an ASP most of them (85.7\%) indicated 'secondary' applications (e.g. human resources, stock management, payroll etc.), rather than the 'critical' ones (e.g. billing, check in, check out). This suggests that even the 'early adopters' are still skeptical about the ASP model and are not ready to adopt the model for applications that they consider as crucial to their property.

A considerable number of pro-ASP respondents also expressed their discomfort with the idea that crucial and confidential data about their hotel would be stored and managed by a server "away from home", emphasizing the issue of control, safety and confidentiality. 
The respondents who rejected the model mainly stated the reasons presented in the "ASP reality check", i.e., loss of control power, security concerns and Internet infrastructure-related factors. They also add problems of interfacing any existing (legacy) property hardware/software with the ASP. However, loss of control, as Exhibit 5 demonstrates, is much stronger than the rest of the reasons.

Exhibit 5 - Reasons for ASP Rejection

\begin{tabular}{|l|l|l|}
\hline Reason & $\begin{array}{l}\text { Number of respondents } \\
\text { mentioning the factor }\end{array}$ & $\begin{array}{l}\text { Total number of mentions } \\
\text { during the survey }\end{array}$ \\
\hline Loss of control power & 53 & 214 \\
\hline Security concerns & 48 & 102 \\
\hline Internet infrastructure & 27 & 82 \\
\hline $\begin{array}{l}\text { Existing (legacy) property } \\
\text { hardware/software }\end{array}$ & 21 & 56 \\
\hline
\end{tabular}

Legacy systems play a significant part in the decision making process. A significant number of respondents (19.8\%) indicated that they were reluctant to abandon the applications they already have in the hotel in favor of an ASP solution. This was supported even if this involved an application which would significantly improve their operations. They felt that 'back-end integration' would be impossible or that the cost of interface and the disruption caused by a change in the existing ICT status in their hotel would defeat the purpose of using an ASP (reduction of ICT cost). A final but equally interesting finding was that $3.8 \%$ of the respondents rejected the idea of using an ASP because "...[they] did not see anyone in [their] direct competition to use this model", illustrating the power of imitation and leadership in ICT penetration in the hospitality industry.

\section{Implications for the Independent Hotelier in the New Economy}

This research provides a number of critical conclusions for the future of ASPs and particularly for their adoption by small and independent hotel properties. Although the sampling method does not allow any great generalization, the study findings raised several concerns that need to be addressed by both ASPs and small properties in order to take advantage of the potential of this technology.

The first is that small independent hoteliers do not seem to believe that ICT gives them any kind of competitive edge. This challenges the assertions of many authors in the hospitality and tourism field ${ }^{31}$. A more careful investigation of the responses, however, reveals a contradiction. On the one hand, some respondents were very keen to state that they do not

\footnotetext{
${ }^{31}$ For example, Buhalis, D. (1994), "Information and Telecommunications Technologies as a Strategic tool for Small and Medium Tourism Enterprises in the Contemporary Business Environment", in Seaton A. et al. (Eds.), Tourism - The State of the Art, pp. 254-275, London: J. Wiley \& Sons; Cho, W. and Olsen, M.D. (1998), "A Case Study Approach to Understanding the Impact of Information Technology on Competitive Advantage in the Lodging Industry", Journal of Hospitality and Tourism Research, Vol. 22, No. 4, pp. 376-394; Sigala, M., Lockwood, A., and Jones, P., (2001), "Strategic Implementation and IT: Gaining Competitive Advantage from the Hotel Reservation Process", International Journal of Contemporary Hospitality Management, Vol. 13, No. 7, pp.364-371.
} 
need ICT to run their hotel, but on the other, they listed a number of benefits they regularly gain from using ICTs. They maintained that only core hospitality and service-related functions can give them an edge over the competitors. However, this approach failed to recognize that ICT often enables them to concentrate on these functions, whilst also enables them to cut costs, achieve differentiation and, ultimately, increase their business competitiveness. The attitude of hoteliers towards ICTs may be attributed to the fact that the majority of hoteliers are alienated from or intimidated by ICTs and tend to assign the ICT function and operations to either system managers or to outsource them to other companies. Hence, hotel managers often fail to appreciate the magnitude of the emerging change as a result of the ICTs. This is illustrated by the fact that almost half of the respondents $(48.1 \%)$ are not directly involved with crucial for their business ICT decisions. They often leave them to third parties, most probably consultants, who may carry their own agendas and not have the best interest of the hotel at heart. Others simply fail to appreciate the potential that ICT offers for their business. Therefore a reliable, unbiased partner who can help them solve their ICT problems in an affordable way can be critical. This partner can provide collective expertise from other properties, offer flexibility and knowledge and allow them to concentrate on what they know and enjoy best: serve their guests.

Despite it's a number of 'teething problems', the hosted application model seems ideal in this situation. No consultants are needed, no ICT specialists need to be employed at the property level, and it offers a value proposition that cannot be ignored. Independent hoteliers, , may find in an ASP a perfect partner who offer the technical expertise and infrastructure that their hotel needs to compete in the arena of the New Economy. They can therefore gain the benefits without having to invest heavily in ICT.

Most of the respondents in this study therefore reported that they would be attracted to this model, mainly by the obvious cost benefits it offers. However, they missed a number of strategic aspects of ASPs as well as most of the additional critical benefits they offer. Smallhotel managers need to realize that the paramount consideration for any networking decisions should primarily be the maximization of flexibility and then the minimization of operational costs. There is no point in building a business network if this does not result in setting resources free to be used in core hotel operations. The hosted application model offers them exactly that flexibility, as they have the opportunity to constantly updating their software in order to cover their future needs.

Small hotel managers were also concerned about the performance, control/ownership of data and security within the hosted application model. As the ASP industry moves from its inception and development stages to its maturity and mass commercial deployment, these concerns are being gradually addressed. The industry gradually stabilize and a number of serious players emerge to provide reliable services. Gradually therefore hoteliers start trusting ASPs and take advantage of the following developments to address their business needs and functions.

- Most ASPs use secure Virtual Private Networks (VPN) or offer Internet connectivity through partnerships with high capacity $(9.6 \mathrm{Gbit} / \mathrm{s})$, fully redundant, scalable global Internet provision (IP) networks. Also, ISDN lines are offered by most telecoms world-wide and broadband connectivity is increasingly available. These developments enable them to improve their web performance through speed and reliability enhancements

- Some ASPs offer auxiliary 'back up' servers within hotel, in case of system failure or network downtime. Increasingly they also assume the responsibility of 'back-end' integration with legacy systems making transactions seamless. These developments aim at addressing data ownership and control concerns. They also comfort nervous hoteliers about the reliable performance of critical applications such as PMSs. More 
recently, a number of ASPs started realizing is that to become 'real partners' with the users of their services they would have to modify their offering in that vein Corio $_{-}$ and Jamcracker for example have started offering their application management services for computing located on customers' premises. This will enable them to increase the confidence of their clientele and to ensure that they serve their customers better.

- Security is also strengthened over the networks with the further development of existing initiatives. Firewalls, PKI, security certificates, etc. are utilized for providing detection of unwanted entries, as well as for offering 'learning' defense systems that accumulate knowledge and empower their defense mechanisms through the experience of previous attacks. These systems, in addition to providing conventional security infrastructure, are able to continually update the security functions with new, unknown types of attacks and to block them on the first strike.

The research demonstrated several benefits of the ASP value proposition as well as a number of concerns and arguments against the hosted application model. Hoteliers need to decide therefore a number of strategic issues, such: "which applications should be outsourced to an ASP" and "how many ASPs should be used" to improve the hotel's ICT infrastructure. The majority of the pro-ASP respondents in this study, indicated that they would use the model for 'secondary' rather than 'critical' applications. This was not surprising, given that the feeling of loss of control was the first issue that respondents noted as a major disadvantage. The numerous teething problems ASPs had in their first few years of life jeopardized their credibilty.

There are no straightforward answers to these questions and different hoteliers will probably adopt dissimilar strategies and solutions. The critical factors determining their decision are the hotel's capability to invest on ICT and the degree of dependence that each hotel manager is prepared to have on its ASP network. According to one school of thought ${ }^{32}$ in order to maintain control of the network environment, the hotel should keep the partner ASPs battling to provide their services. A good strategy would be to periodically re-configure the network (e.g., every two years), keeping part of the applications in-house and using them as an incentive for the most efficient and most trustworthy ASP. This approach will enable the hotel to team up only with the 'best-of breed' pure-plays. The downside of such a strategy is that systems are often not compatible and the transition from one ASP to another may be proven problematic. It also involves a high level of involvement for the management. Increasingly however, there is also the option of 'strategic partnership' with a business process outsourcer (such as Accuvia) who monitor and manage the majority -if not all- of the hotel's applications and report to the owner/manager who makes the final decisions.

Small hotel managers may take advantage of the instability in the ASP industry by negotiating their terms on Service Level Agreements (SLAs) with eager service providers. These should include the normal service and payment details as well as very specific 'exit strategies', in the case the ASP fails to provide the agreed service levels or stops its operation. Hoteliers may also demand an articulated process, with provisions for a gap analysis and coverage (e.g., case of incompatibility with a new ASP). In this case, should the collaboration be terminated due to a breach of contract, the ASP will have to examine the gaps and undertake the task of bridging the differences between its provision and the one of its successor.

\section{In Conclusion}

\footnotetext{
${ }^{32}$ Lacity, M.C, Willcocks, L.P. and Feeny, D.F. (1995) "IT Outsourcing: Maximizing Flexibility and Control", Harvard business Review, Vol. 73, No.3, pp.84-95.
} 
In the New Economy some innovative hoteliers (regardless of their size) seem to be taking advantage of the power, flexibility and opportunities offered by the front- and back-end business networks they have created and enjoy the promised benefits. However, these advantages may be enjoyed only if outsourcing decisions are well informed and not influenced by the 'cost reduction myopia' or 'third parties' who may have vested interests.

The hospitality industry's stability in the New Economy is constantly threatened by a constant repositioning of its incumbents, frequent entry of new players, new technologies, rapid growth but also collapse of markets due to factors beyond the control of hoteliers. Although independent hoteliers seem to lag behind in the effective use of ICT, they gradually appreciate that they will have difficulties in maintaining their competitiveness in this new competing environment. By not accepting the new rules of the game and by either ignoring or remaining alienated from ICT they are competing with one hand tied behind their backs, having a much harder time to survive - never mind succeed. One way to 'untie' the hand is by building a webenabled network in which they can leverage the assets of other connected parties to gain the flexibility needed to continuously create competitive advantages based on their own core competencies. The ASP model of outsourcing, despite the challenges that still need to be overcome, gives them the perfect chance to improve their ICT infrastructure and be able to compete with every other player in the digital arena on equal footing. 